Ethiopian Journal of Environmental Studies \& Management 9(5): 554 - 566, 2016.

ISSN:1998-0507

doi: http://dx.doi.org/10.4314/ejesm.v9i5.3

Submitted: February 06, 2016

Accepted: September 02, 2016

\title{
ASSESSMENT OF THE PATTERNS OF RAINFALL IN NORTHERN NIGERIA
}

\author{
ADAKAYI, P.E., ${ }^{1}$ OCHE, C.Y. ${ }^{2}$ AND *ISHAYA, S. ${ }^{1}$ \\ ${ }^{1}$ Department of Geography and Environmental Management, University of Abuja, Nigeria \\ ${ }^{2}$ Department of Geography and Planning, University of Jos, Nigeria
}

\begin{abstract}
This study assessed rainfall variations in Northern part of Nigeria. To achieve this aim, the study sets out the following objectives; determine variations in rainfall characteristics in terms of extreme rainfall amounts, variability and ranges, use the time series to determine any trend in the change (upward or downward), predict values for the period; 2007 2030, which will also be subjected to the time series analysis and account for the causes of rainfall variability in the study area. The data for the study was collected from the Nigerian Meteorological Agency for eleven (11) stations for a period of thirty-six (36) years. Simple statistical measures of mean, median, maximum and minimum, standard deviation, variance, skewness, kurtosis and coefficient of variability were used for discerning the patterns and distribution of rainfall. The results achieved indicate that the region could be divided into two periods on the basis of lower rainfall (1970's and 1980's) and the periods of higher rainfall (1990's and 2000's). During the predicted period; 2007 2030, rainfall declines until 2019 and from 2020, rainfall begins to increase until 2030. The southern part of the region has higher rainfall compared to the northern parts. There is a general increase in rainfall in the forecast period. The work recommended that more of this type of study be carried out in other regions of Nigeria. The results show that no signal has really been detected. We should devote more attention to regional studies of current climatic behaviours in various regions of Nigeria.
\end{abstract}

Key Words: Pattern, Rainfall, Maximum, Minimum, Variability, Northern Nigeria

\section{Introduction}

Throughout the history of earth, climates (global, regional, and local) have never been static. The non-static natures are in various magnitudes ranging from variability through fluctuations, trends, and abrupt to gradual changes. Analyses of proxy data from tidal waves, and changing sea and lake levels; tree rings, pollen counts and ice-core have shown that climatic changes have been dramatic on time scales of 10,000 years or more (Oladipo, 1991).

We know that the earth had entered and emerges from a series of ice-ages. It is believed that variability, in terms of fluctuation or trend is an inherent attribute of climate or weather. What is crucial is the degree of variability that climate is subject to as well as duration of such variability (Ayoade, 2003). He also noted that minor fluctuations or

*Corresponding Author: Ishaya, S.

Email: ishayasunny@yahoo.com 
variations constitute not more than a "noise" in the climate series and that man can easily adapt to such minor variations. However, when fluctuations in climate constitute significant departures from normal conditions or become prolonged to constitute a new climate state, then there is problem of adjustment and the environment, man and his activities become very vulnerable. The rapidity of variations or change in climate also heightens the vulnerability of man, his socio-economic activities and the ecosystems in general to change.

The IPCC (1990) has shown that the world climate has been changing and will continue to change. The question of climate change, fluctuations, variations, and trend is no longer debatable. What is not clear is the nature of this change, fluctuations, variations and trend in specific regions like northern Nigeria. This region's main occupation is farming, mainly rain-fed agriculture. Any change, variation, or fluctuation in climate whether gradually or rapidly will seriously affect the occupation of the inhabitants of this region. Therefore, a thorough knowledge of the behaviour of rainfall, present or future, will contribute significantly to the wellbeing of the people. Predictions have been made about northern Nigeria where we know that climatic conditions are becoming more arid, the Sahara desert is advancing and the Lake Chad is rapidly receding. It is therefore very pertinent to study

For nearly five decades in the twentieth century, rainfall amounts in Africa remain relatively high, allowing local inhabitants to sustain or even increase crop yields, cattle herds and human population levels (Dirmeyer, 2003). However, in the early 1960's the rainfall amounts declined in the region and by the early 1970's, the human and ecological tragedy of the Sahel was a serious matter receiving attention worldwide. We know that climate in African dry lands has varied considerably through time, and there is no reason to believe that today's climate will persist into the future. Climate change in African dry lands is the rule not the exception (Dirmeyer, 2003).

Africa is no exception in experiencing these human induced changes in climate, although much work still need to be done in separating the "natural" factors of climate change from the human induced ones (Xue, 1997). The seasonally wet months of June, July and August in the Sahel suggests that different GCM simulation yield (sometimes) very different regional rainfall responses to a given greenhouse gas forcing. Most climate change scenarios in the Sahel do not represent adequately past, present and future estimates of climate of the region (Ferro, 2005).

Climate models show the precipitation response to be far more variable than temperature. It is also reported that winter precipitation increases are likely across most of Europe as a result of increases in atmospheric moisture content and storm activity (McGregor et. al., 2001). In summer, Europe wide- decreases have been predicted because of increased blocking activity at over the north eastern parts of the north Atlantic. The changes are not so obvious in spring and autumn (Giorgi, 2004).

Giorgi, (2004) identified overgrazing in the Sahel as the major cause of droughts. To him overgrazing could result in increasing surface runoff and a 
reduction in available soil moisture. The "expanding Sahara" could be the result of local activities and not the industrialization of the mid latitudes of the Northern Hemisphere. Ferro (2005) similarly argued that overgrazing in dry land areas could increase albedo, reduce surface temperatures, and near surface air temperatures, stabilize the atmosphere, and reduce local rainfall levels.

Future changes in the mean seasonal rainfall in Africa are less defined. Under BI-low scenario, relatively few regions in Africa experience a change in either December, January, and February (DJF) or June, July, and August (JJA) rainfall that exceeds the one sigma level of natural rainfall variability. The exceptions are parts of equatorial east Africa where rainfall increases by $5 \%$ to $30 \%$ in DJF and decreases by $5 \%$ to $10 \%$ in JJA. With more rapid global warming (e.g. the B2, A1 and high scenarios) increasing areas of Africa experience changes in DJF or JJA rainfall that exceed the one sigma level of natural rainfall variability (Griffin, 2001) found that Sahel temperature and precipitation are very sensitive to soil moisture levels. That Sub-Sahara desertification leads to

a) A reduction in moisture flux and rainfall in the Sahel.

b) An increase in moisture flux and rainfall in the south of the Sahel.

The research aimed at examining the nature and extent of rainfall variation in northern Nigeria. The objectives were to determine rainfall variability in the study area, determine the causes of variation of rainfall, if it exists and to predict future rainfall amounts in northern Nigeria. The study is based on the assumption that the variations in rainfall in northern Nigeria is still within the normal level for the study period.

\section{Study Area}

The location, position and size of the study area is bounded by latitudes $90 \mathrm{~N}$ and $130 \mathrm{~N}$ and longitudes $30 \mathrm{E}$ and $15 \mathrm{E}$ (Fig 1). It has a population of about $54,758,909$ by the 2006 census (Table 1 ). 


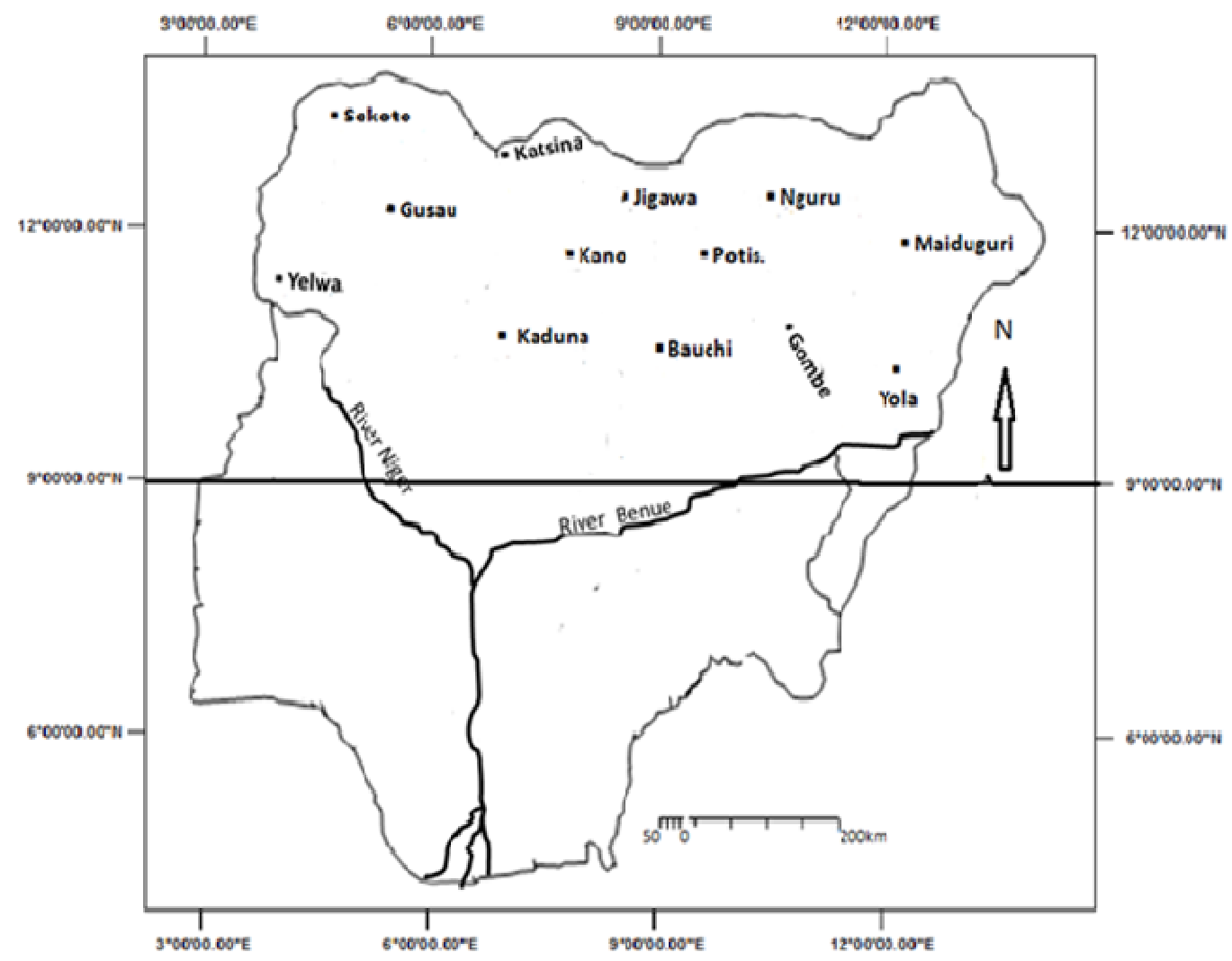

Figure 1: Nigeria Showing Climatic Stations Study Area

Table 1: Population of study Area by State

\begin{tabular}{lll}
\hline S/NO & STATE & POPULATION \\
\hline 1 & Bauchi & 4676465 \\
2 & Kebi & 3238628 \\
3 & Kano & 9383682 \\
4 & Katsina & 5792578 \\
5 & Kaduna & 6066562 \\
6 & Borno & 4651193 \\
7 & Yobe & 2321591 \\
8 & Sokoto & 3696999 \\
9 & Adamawa & 3168101 \\
10 & Zamfara & 3259846 \\
Total & & 54758909 \\
\hline
\end{tabular}

Source: 2006 Census Figures

It is majorly made up of the Sudan Savannah grassland and Guinea Savannah. The topography is even and Precambrian igneous and metamorphic rocks of the basement complex are the most common. But peaks such as the Mambila Plateau and the Adamawa highlands are mostly of granites and volcanic rocks (Oguntoyibo, Areola, and Filani, 1978). The major rivers traversing the place are Rivers Benue and Niger as the southern boundaries and Rivers Rima, Hadejia, Nguru, Gana, Jamaare and fairly large area covered by the Lake Chad at the North Eastern corner.

Ground water is highly used in the region often to a depth of 100 meters for a borehole. Static water could be found at the depths of 40 meters. The region has about four(4) of the river basins in Nigeria, namely; upper River Benue basin, Lake Chad basin, Hadejia-Jamaare River basin and Sokoto-Rima river basin. Deforestation is active in the region 
contributing significantly to desertification and drought.

\section{Methodology}

The data used in the study are purely secondary data collected from the Nigerian Meteorological Agency, Maitama, Abuja. Synoptic stations in Nigeria submit data collected in their stations to the Agency Headquarters. Necessary adjustments (interpolation and averaging) were carried out for the cases of missing data. The rainfall data was collected for eleven (11) stations for a period of thirty-six (36) years. The stations involved are Bauchi, Gusau, Kano, Katsina, Kaduna, Maiduguri, Nguru, Potiskum, Sokoto, Yola, and Yelwa (figure 1).

Other derivatives of these data were computed and used for further analysis. Such derivatives include averages, range, monthly and annual totals all for each station and each year. The data were then subjected to trend analysis to achieve our stated objectives.

The Time Series Analysis employed will help to verify the stated assumptions on the temporal and spatial trends of rainfall. Rainfall prediction for 2007 2030 was also carried out. The major tool was the SPSS software package for the analysis. The normality test, Fisher's standardized coefficient of skewness $\left(Z_{1}\right)$, and kurtosis $\left(Z_{2}\right)$ were used to determine if the data collected are normally distributed to enable us use the parametric statistics in their further analysis. Further analysis includes the use of Box-Ljung statistics showing both auto - correlation and partial auto correlation, these help to show if rainfall of the previous years have any relationship with the succeeding year(s). The correlation coefficients $\left(r_{p}\right)$ were calculated and the probability of significance of the coefficients was also calculated including the plot of the graph of the coefficients.

In this study, rainfall summaries were conducted in two forms:

a) Rainfall summaries by the stations in order to explain the spatial variations

b) Rainfall summaries by year to explain the temporal variations.

Further analyses were carried out using frequency histograms. The times series analysis was also undertaken to observe trends both in the data collected (1971 2006) and the forecast from $2007-2030$.

\section{Results}

\section{Rainfall Summaries by Stations}

The highest amount of mean annual rainfall was recorded in Kaduna with the sum of $1218.21 \mathrm{~mm}$ followed by Bauchi $(1001.45 \mathrm{~mm})$ and then Gusau $(908.58 \mathrm{~mm})$ on the other hand; the least amount of mean annual rainfall was recorded at Nguru with the sum of $409.78 \mathrm{~mm}$ followed by Katsina with the sum of $534.88 \mathrm{~mm}$ and then Maiduguri with the sum of $562.37 \mathrm{~mm}$. 
Table 2: Summaries of Mean Annual Rainfall by Stations in the Study Area

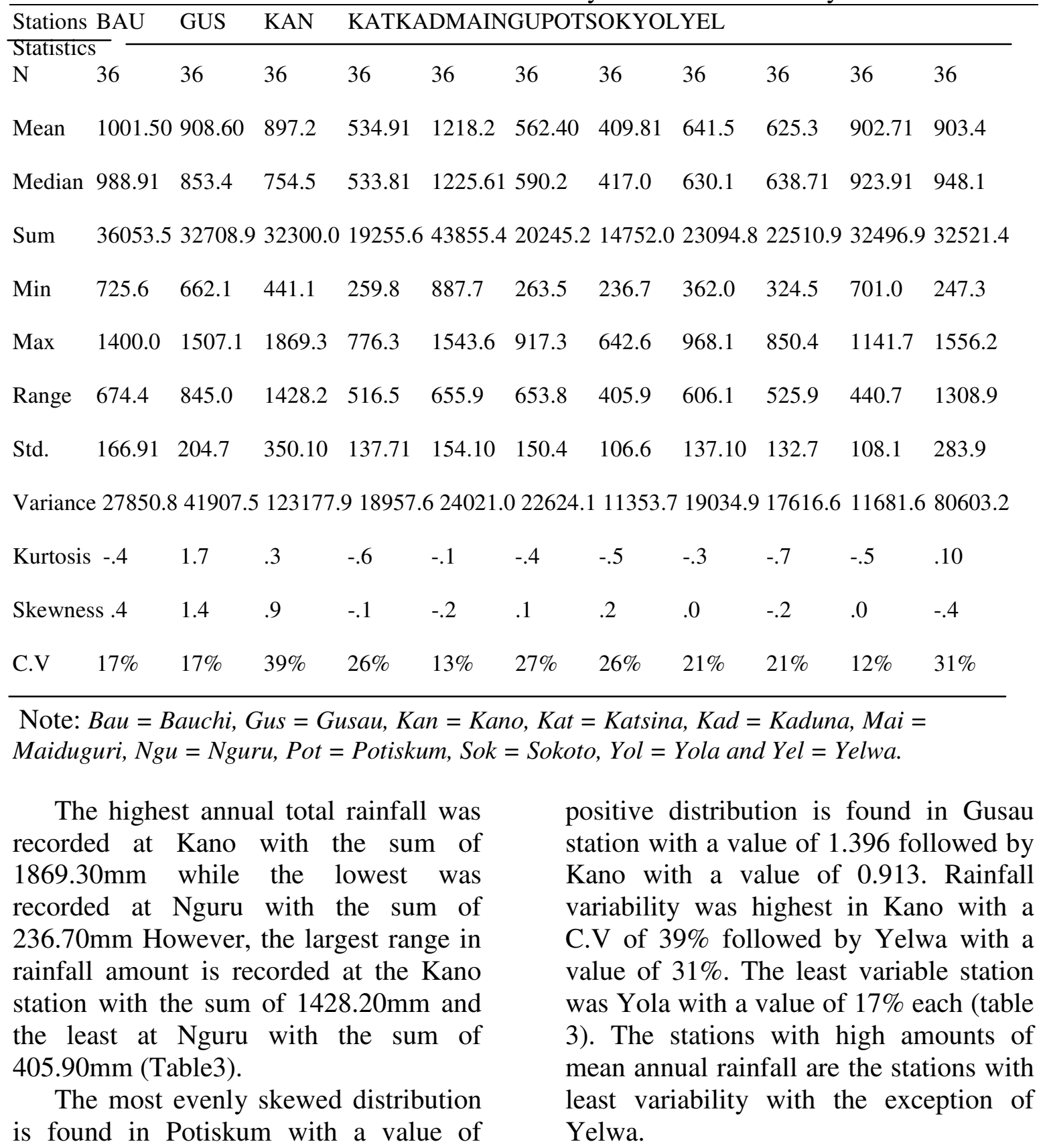

0.034. However, the most uneven 
Ethiopian Journal of Environmental Studies and Management Vol. 9 no.5 2016

Table 3: Summaries of Mean Annual Rainfall by year in the Study Area

\begin{tabular}{|c|c|c|c|c|c|c|c|c|c|c|c|c|}
\hline year & \multicolumn{12}{|c|}{ Statistics } \\
\hline & $\mathrm{N}$ & mean & median & Sum & Min & Max & Range & Std.D & Var & Kurt & Skew & C.V\% \\
\hline 2006 & 9 & 816.1 & 887.7 & 8976.7 & 409.5 & 1057.3 & 647.8 & 214.1 & 45830.5 & -.7 & -.7 & 26 \\
\hline 2005 & 9 & 875.3 & 917.3 & 9628.1 & 448.6 & 1375.5 & 926.9 & 253.1 & 64041.8 & .5 & .2 & 29 \\
\hline 2004 & 11 & 833.1 & 866.0 & 9164.0 & 293.7 & 1379.0 & 1085.3 & 316.0 & 99883.9 & -.1 & .2 & 38 \\
\hline 2003 & 11 & 956.10 & 943.8 & 10526.8 & 481.3 & 1543.6 & 1062.3 & 363.1 & 131865.4 & -1.1 & .5 & 38 \\
\hline 2002 & 11 & 779.1 & 768.7 & 8570.6 & 444.1 & 1306.4 & 862.3 & 249.3 & 62173.6 & .9 & .7 & 32 \\
\hline 2001 & 11 & 924.5 & 777.3 & 10169.4 & 416.0 & 1613.0 & 1197.0 & 350.7 & 122994.4 & -.2 & .7 & 38 \\
\hline 2000 & 11 & 828.4 & 732.6 & 9112.5 & 353.8 & 1241.8 & 888.0 & 273.4 & 74761.8 & -.8 & -.0 & 33 \\
\hline 1999 & 11 & 984.1 & 957.2 & 10824.6 & 446.7 & 1556.2 & 1109.5 & 376.1 & 141444.9 & -1.3 & .1 & 38 \\
\hline 1998 & 11 & 958.10 & 1005.6 & 10548.8 & 422.1 & 1869.3 & 1447.2 & 394.90 & 155939.2 & 2.1 & .9 & 41 \\
\hline 1997 & 11 & 840.5 & 787.6 & 9245.5 & 502.8 & 1293.6 & 790.8 & 287.0 & 82369.7 & -1.0 & .5 & 34 \\
\hline 1996 & 11 & 838.3 & 885.9 & 9220.8 & 259.8 & 1214.7 & 954.9 & 304.8 & 92907.8 & -.6 & -.5 & 37 \\
\hline 1995 & 11 & 756.8 & 699.7 & 8325.2 & 370.6 & 1183.3 & 812.7 & 280.8 & 78821.3 & -1.2 & .3 & 37 \\
\hline 1994 & 11 & 887.2 & 785.2 & 9759.4 & 426.6 & 1507.2 & 1080.6 & 370.6 & 137366.8 & -.5 & .7 & 42 \\
\hline 1993 & 11 & 789.7 & 920.2 & 8686.70 & 262.0 & 1242.2 & 980.2 & 349.4 & 122107.1 & -1.3 & -.3 & 44 \\
\hline 1992 & 11 & 829.8 & 927.0 & 9128.1 & 333.1 & 1344.2 & 1011.1 & 343.5 & 118026.1 & -1.4 & -.0 & 41 \\
\hline 1991 & 11 & 811.5 & 774.9 & 8926.4 & 333.9 & 1405.1 & 1071.2 & 330.7 & 109361.7 & -.4 & .1 & 41 \\
\hline 1990 & 11 & 657.5 & 654.2 & 7232.5 & 410.5 & 1022.0 & 611.5 & 207.6 & 43106.6 & -.10 & .4 & 32 \\
\hline 1989 & 11 & 742.1 & 784.3 & 8163.0 & 338.6 & 996.6 & 658.0 & 199.6 & 39822.7 & -.0 & -.8 & 27 \\
\hline 1988 & 11 & 857.1 & 940.3 & 9428.2 & 320.6 & 1188.1 & 867.5 & 255.3 & 65194.5 & .4 & -.9 & 30 \\
\hline 1987 & 11 & 609.0 & 506.0 & 6699.0 & 250.2 & 1200.1 & 949.9 & 304.2 & 92546.1 & -.2 & .8 & 50 \\
\hline 1986 & 11 & 739.6 & 809.4 & 8136.1 & 240.6 & 1095.7 & 855.1 & 267.3 & 71471.8 & -.8 & -.5 & 36 \\
\hline 1985 & 11 & 671.5 & 655.6 & 7386.0 & 414.1 & 1223.1 & 809.0 & 259.2 & 67176.3 & .4 & .9 & 39 \\
\hline 1984 & 11 & 641.1 & 478.7 & 7051.6 & 332.4 & 1173.2 & 840.8 & 287.2 & 82486.9 & -.9 & .6 & 45 \\
\hline 1983 & 11 & 589.2 & 583.9 & 6480.9 & 236.7 & 902.4 & 665.7 & 226.9 & 51510.7 & -1.1 & -.2 & 36 \\
\hline 1982 & 11 & 718.1 & 638.1 & 7899.4 & 354.0 & 1312.8 & 958.8 & 293.2 & 85964.9 & .1 & .8 & 41 \\
\hline 1981 & 11 & 767.5 & 733.5 & 8442.8 & 428.9 & 1250.8 & 821.9 & 290.4 & 84307.5 & -.9 & .6 & 38 \\
\hline 1980 & 11 & 825.3 & 881.4 & 9078.8 & 339.6 & 1287.2 & 947.6 & 269.8 & 72808.3 & -.0 & -.1 & 33 \\
\hline 1979 & 11 & 865.4 & 776.3 & 9519.0 & 587.8 & 1476.0 & 888.2 & 262.9 & 69150.4 & 1.8 & 1.3 & 30 \\
\hline 1978 & 11 & 862.8 & 887.4 & 9490.9 & 496.7 & 1437.8 & 941.1 & 303.8 & 92305.0 & -.5 & .4 & 35 \\
\hline 1977 & 11 & 735.5 & 786.2 & 8090.9 & 362.0 & 982.4 & 620.4 & 186.10 & 34967.3 & .1 & -.8 & 25 \\
\hline 1976 & 11 & 772.7 & 689.9 & 8499.6 & 430.9 & 1350.5 & 919.6 & 310.9 & 96700.8 & .4 & 1.3 & 40 \\
\hline 1975 & 11 & 756.8 & 656.9 & 8324.4 & 557.4 & 1289.1 & 731.7 & 245.9 & 60503.6 & -.6 & 1.3 & 32 \\
\hline 1974 & 11 & 793.2 & 671.2 & 8725.5 & 472.4 & 1441.7 & 969.3 & 284.6 & 80976.5 & 1.8 & 1.3 & 36 \\
\hline 1973 & 11 & 551.0 & 441.1 & 6061 & 258.9 & 1226.1 & 967.2 & 288.9 & 83507.2 & 1.8 & 1.3 & 36 \\
\hline 1972 & 11 & 614.8 & 549.1 & 6762.4 & 247.3 & 1231.7 & 984.4 & 295.6 & 87373.7 & .5 & 1.3 & 48 \\
\hline 1971 & 11 & 682.6 & 628.5 & 7508.5 & 373.5 & 1268.30 & 894.8 & 280.6 & 78751.7 & .5 & 1.3 & 41 \\
\hline
\end{tabular}

Rainfall Summaries by Year

The highest mean annual rainfall was recorded in 1999with the sum of
$984.06 \mathrm{~mm}$ followed by 1998 with the sum of $958.98 \mathrm{~mm}$ and then the year 2003 with the sum of $956.98 \mathrm{~mm}$. 
Assessment of the Patterns of Rainfall in Northern Nigeria................ADAKAYI et al.

Table 4: Time Series Modeler

\begin{tabular}{llll}
\hline Model Description & & & \\
\hline \multirow{3}{*}{ Model ID } & Mean Annual & Model_ & Model Type \\
& $\begin{array}{l}\text { Values of } \\
\text { Rainfall }\end{array}$ & 1 & ARIMA $(1,2,0)$ \\
\hline
\end{tabular}

Forecast Model Mean Annual Values of Rainfall -Model_1

\begin{tabular}{l|lll}
\hline \multicolumn{5}{l}{} & & & \\
\hline year & forecast & UCL & LCL \\
\hline 2007 & 839.6793 & 1078.024 & 601.3344 \\
2008 & 800.7385 & 1175.081 & 426.396 \\
2009 & 813.9046 & 1428.400 & 199.4094 \\
2010 & 788.7481 & 1626.182 & -48.686 \\
2011 & 796.6090 & 1916.063 & -322.845 \\
2012 & 781.2071 & 2183.177 & -620.763 \\
2013 & 786.9419 & 2510.509 & -936.625 \\
2014 & 778.7865 & 2832.014 & -1274.44 \\
2015 & 784.3738 & 3195.916 & -1627.17 \\
2016 & 781.9041 & 3563.178 & -1999.37 \\
2017 & 788.5752 & 3962.268 & -2385.12 \\
2018 & 790.8198 & 4369.729 & -2788.09 \\
2019 & 799.3411 & 4802.498 & -3203.82 \\
2020 & 805.6953 & 5246.311 & -3634.92 \\
2021 & 816.5438 & 5711.275 & -4078.19 \\
2022 & 826.634 & 6188.626 & -4535.36 \\
2023 & 840.190 & 6684.39 & -5004.18 \\
2024 & 853.696 & 7193.126 & -5485.74 \\
2025 & 869.979 & 7718.408 & -5978.46 \\
2026 & 886.910 & 8256.82 & -648300 \\
2027 & 906.112 & 8810.456 & -6998.22 \\
2028 & 926.310 & 9377.14 & -7524.50 \\
2029 & 948.525 & 9958.077 & -8061.04 \\
2030 & 971.927 & 10551.86 & -860800 \\
\hline
\end{tabular}

Incidentally the last two years followed one another that is 1998 and 1999. The least mean annual total of rainfall were found in 1973 with the sum $551.05 \mathrm{~mm}$ and 1987 with the sum of $609.00 \mathrm{~mm}$. From the values here, there seem to be lower rainfall between 1971 and 1990 than 1991 and 2006 (Table 4).

The minimum amount of rainfall occurred in 1983 with the sum of 236.70 followed by 1986 with the sum of 240.60 and 1987 with the sum of $250.20 \mathrm{~mm}$. The least amounts of rainfall occurred in the 1980's. On the other hand, the highest amounts of rainfall occurred in 1998 with a value of $1869.30 \mathrm{~mm}$ followed by 1999 with the sum of $1556.20 \mathrm{~mm}$, then 1994 with the sum of $1507.20 \mathrm{~mm}$. This indicates that the 1990's had the highest amounts of rainfall just like the mean annual rainfall. 
The distribution of rainfall is most even in 1992 with a skewness of -0.006 followed by 1991 with a value of 0.079 , then 1980 with a value of -0.061 . The most uneven years are 1974, 1973, and 1979 with values of $1.461,1.353$ and 1.320 respectively (Table 3 ). This is an indication that the 1970's presented the most problematic years in rainfall distribution. The year 1986 was the most variable year with regards to rainfall distribution with a C.V. of $50 \%$ followed by 1972 with a value of $48 \%$ and 1983 with a value $45 \%$. The least rainfall variability occurred in 1977 with a value of $25 \%$ followed by the year, 2006 with a value of $27 \%$.

The spatial variability in the study area reveals that the lower latitudes have lower rainfall variability than the higher latitudes; this is expected as it agrees with the general trend in Nigeria. That is the variability is related to the upward and downward movement of the ITCZ as controlled by the NE and SW air mass movement (figure 2).

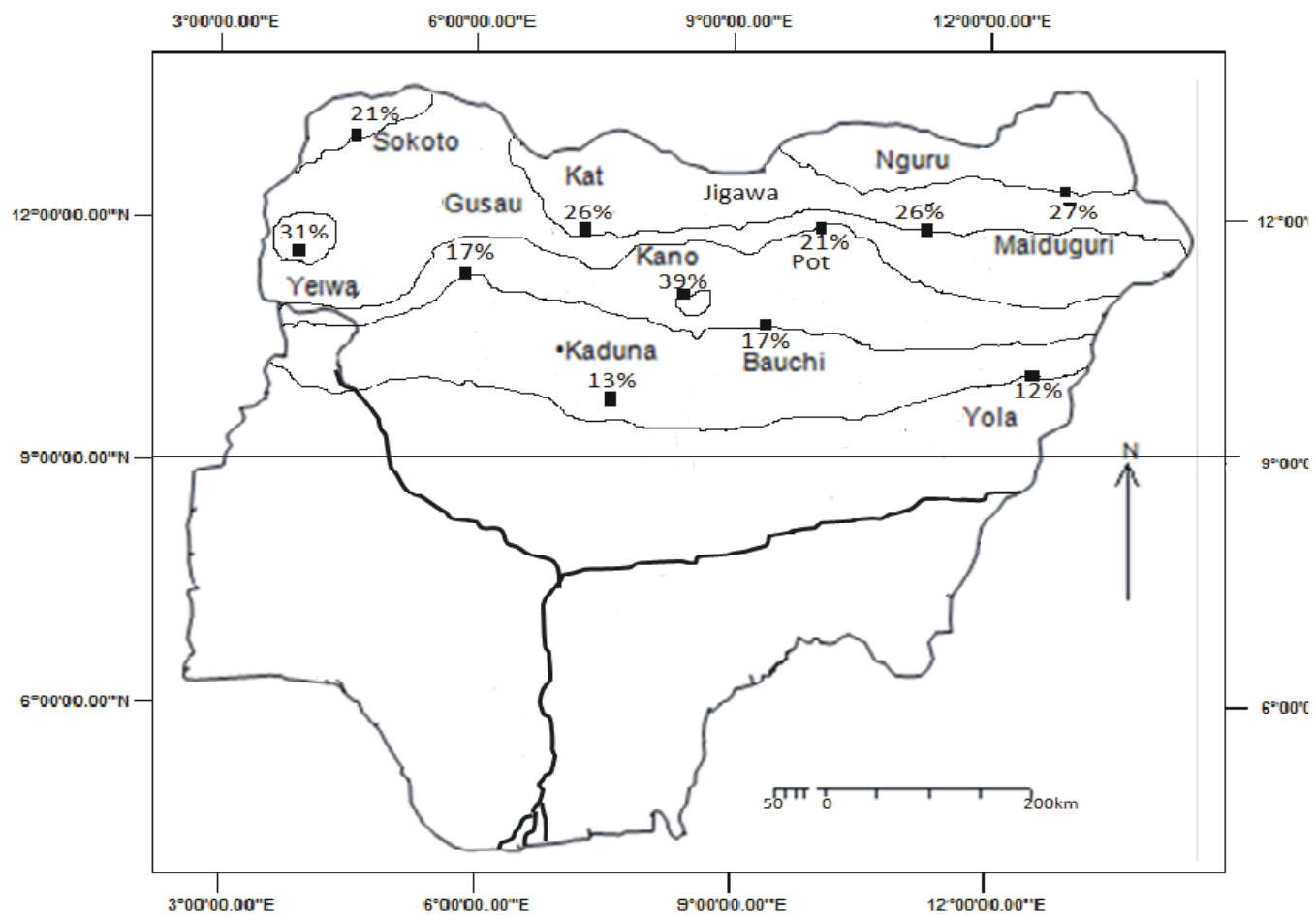

Figure 2: Rainfall Variability in the Study Area

\section{Time series Analysis}

Time series analysis was also carried out using trend lines with respect to the mean values. This enabled the researcher to discern whether there exist increasing or decreasing trends in the distribution of rainfall during the thirty - six (36) years.
The straight line equation of the time series yielded $y=5.86 x+890.6$ for the thirty - six (36) years of data. This line indicates a continuous rise from 1971 to 2006 (fig. 3) 


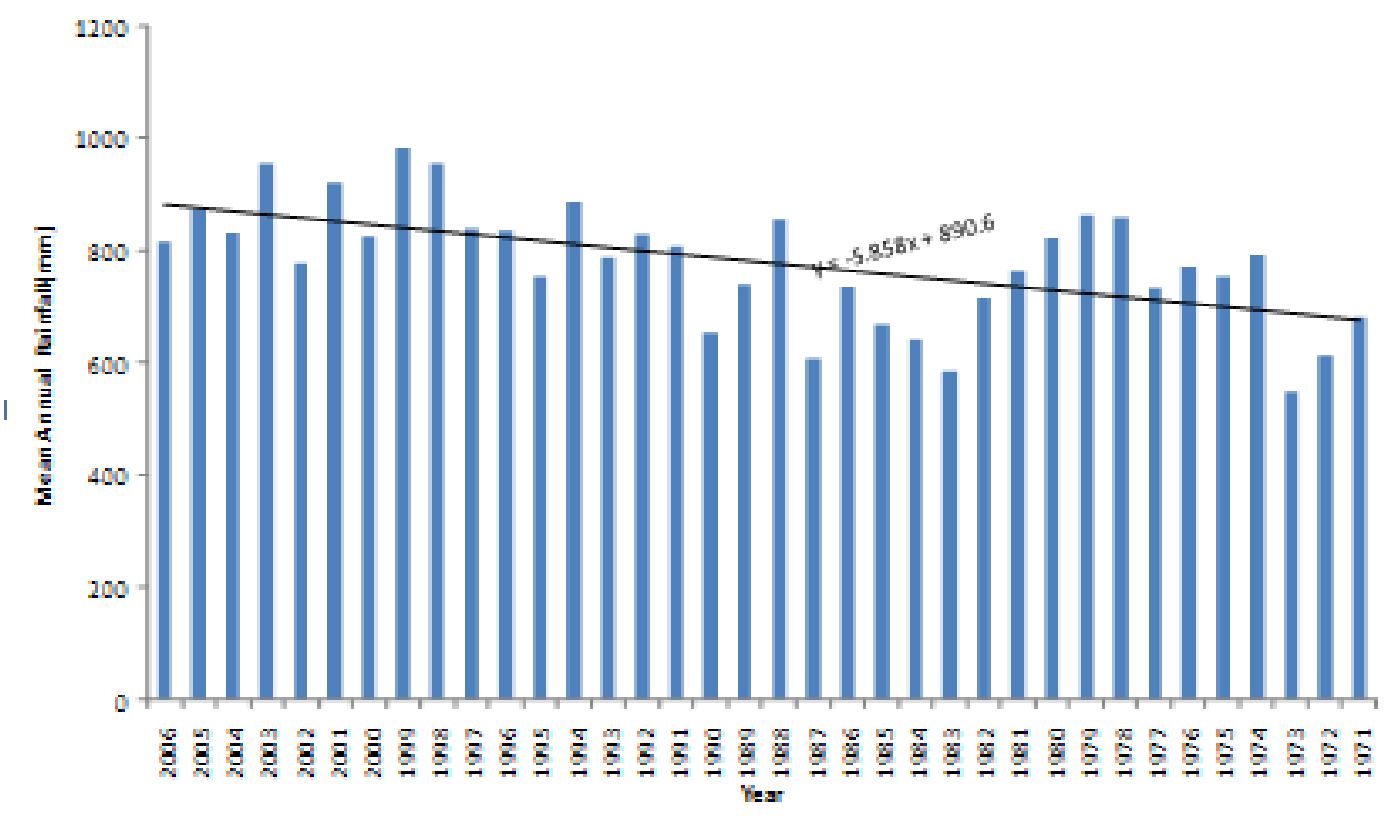

Figure 3: The time series graph of the mean annual rainfall in all stations between 1971 and 2006

This is evidence that there is improved rainfall in the study area. The time series was also applied to the forecast values of mean annual rainfall of 2007 to 2030. This yielded a straight line equation of the form $y=6.675 x-1263.9$. The result also shows that there was large compliance between the straight line expression forecast values with $\mathrm{R}^{2}=$ 0.607 or $60.7 \%$ (figure 4).

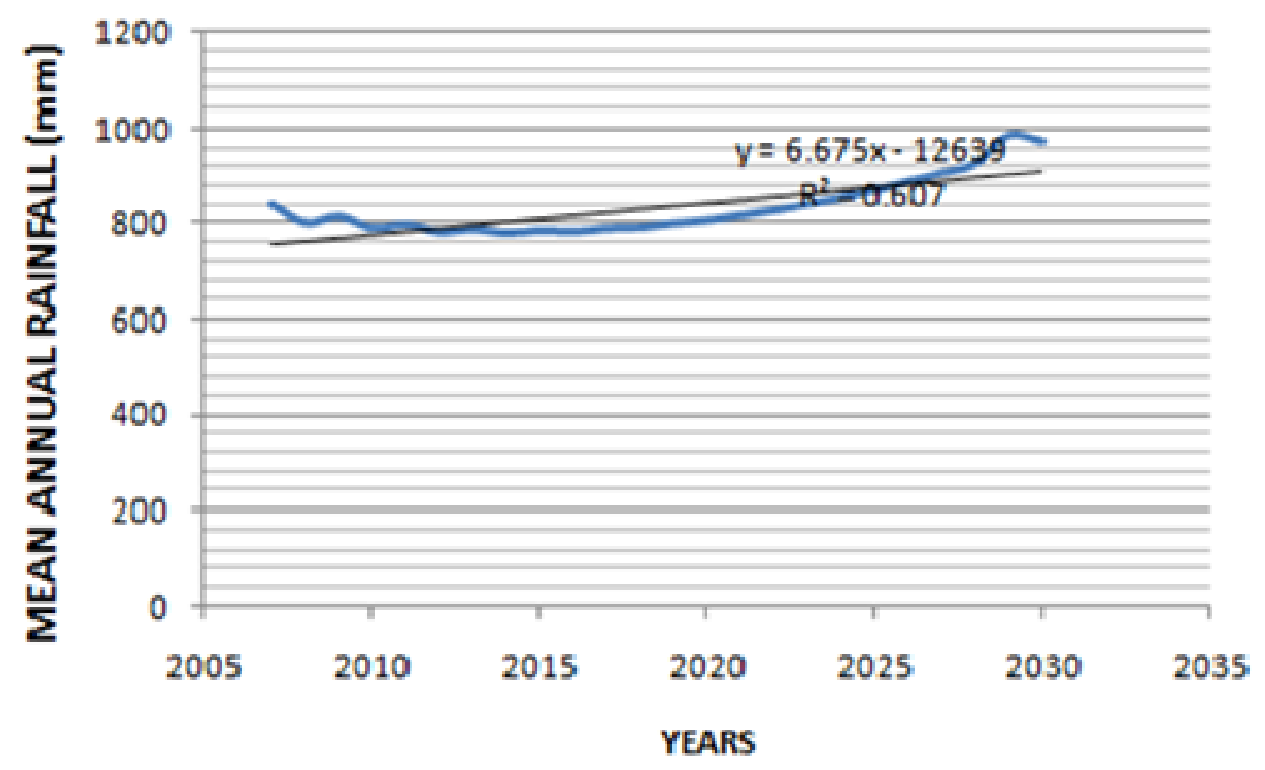

Figure 4: The time series graph of the mean annual rainfall in all stations between 2007 and 2030 (forecast) 
This is saying that the forecast values are correct to as much as $60.7 \%$. Generally there will be a gradual increase in rainfall from $778.8 \mathrm{~mm}$ in 2014 to $971 \mathrm{~mm}$ in 2030 , a difference of $93.1 \mathrm{~mm}$ in 23 years (Table. 4). The forecast model used is the ARIMA $(1,2,0)$. This is the most appropriate.

\section{Discussion}

The northern parts of the study area are in the heart of the Sahel where the least amounts of rainfall occurs. From the results we can talk about two (2) phases of rainfall regime in the study area:

i. $\quad$ The dry years $(1971-1990)$

ii. The wet years $(1991-2006)$

The lean years of harvest and drought and the dislocation of people and many more attendant problems are associated with the dry years of 1971 to 1990 . This agrees with assertion by Oladipo (1991). However, most of the years indicate negative departures from the mean.

It is interesting to note that in 1985, 1987, and 1988, all the stations have lower rainfall values than the mean. With higher rainfall amounts and decreased rain days the likelihood of intense and attendant consequences of flash floods, destruction of lives and properties, and rivers overflowing their banks abound.

Rainfall varies both in time and space in the region, but there is no specific pattern of variability. The variability in station specific, there is no South - North nor West - East observed general pattern. This goes to say that planting activities will have to be localized.

That Northern Nigeria is receiving more rainfall now means, halting the advancement of the Sahara, greening of the Sahara and expansion of the Lake Chad. Therefore planning for water resources, forestry and agriculture will have to take note of this. There is therefore an expectation of increased agricultural yield. Of course, the cries of famine, drought and desert encroachment of the 1970's has declined.

In those earlier years of the 1970's the over - ambitious agrarian programmes/schemes like the Chad Basin Development Authority, the Hadejia Jamare River Basin and the Sokoto Rima River Basins must have contributed to the due drying up of the region. One of such examples is the total removal of vegetation cover to engage in mechanized agriculture.

Increases in local rainfall could be as a result of conscious efforts at afforestation programmes especially in the dry years. This is supported by Xue and Shukla (1996) that land degradation would cause both increase in local temperature and decrease in in rainfall amounts, also that afforestation could increase rainfall.

\section{Summary and Conclusions}

The research sets out to examine the variations in rainfall in Northern Nigeria. The data was collected from eleven (11) synoptic stations for a period of thirty six (36) years from the Nigerian Meteorological Agency, Abuja.

The data was subjected to a series of analyses including the ARIMA Time Series Modeller to forecast rainfall from 2007 to 2030.

In summary, the research yielded the following results:

- That the region could be divided into two periods; the 1970's and 1980's of less rainfall than normal and the 
1990's and 2000's with higher rainfall than normal.

- During the forecast period, 2007 to 2030; rain continues to decline until 2019 and begins to improve from 2020 to 2030.

- The southern part of the study area has higher rainfall compared to the northern part.

This greatly agrees with other results and also the forecast period.

At the end of the research, it is recommended that similar works be carried out in other parts of the country and other regions of Africa where corresponding researchers have not been done like the developed countries.

\section{Recommendations}

At the end of the work, it is pertinent to draw up the following recommendations;

1. It has been proven as at today, the rainfall has not changed significantly to warrant the attention been paid to impact analysis, adjustment patterns and mitigation measures instead, closer watch should be mounted in all regions to monitor the emerging pattern. This will help us to match simulations with reality.

2. Like earlier stated, specific model building should be enabled upon in specific regions like Northern Nigeria for a better fitting of models to realities on the ground.

3. Land use must continue to be monitored to determine their effects on changes in rainfall amounts and distribution.

\section{References}

Adakayi, P.E. (2012). An Assessment of Rainfall and Temperature Variation in Part of Northern Nigeria. Unpublished Ph.D Thesis Submitted to the Department of Geography and Environmental Planning, University of Jos, Plateau State, Nigeria.

Areola, O. (1978). "Soils and Vegetal resources" in Oguntoyinbo, J.S., Areola, O.O. and Filani, M. (ed)(1978) A geography of Nigeria Development. $\quad 2^{\text {nd }}$ edition. Heinemann Educational Books (Nig) Ltd.

Ayoade, J.O. (2003). Climate Change: A Synthesis of its Nature, causes, Effects and Management Vantage publisher Ibadan.

Clausen, M. (2001). "Biogeophysical Feedbacks and the Dynamics of Climate" in Schulze, E. D., Harrison. S. P., Heimann, M., Holland, E.A., Lloyd, J., Prentice, I.C., and Schimel, D (eds.), Global Biogeochemical Cycles in the Climate system, Academic Press, San Diego, pp.61-71.

Dirmeyer, P.A. (2003). The role of the land surface background State in climate predictability. Journal of Hydrometeorology. 4: 599-610.

Ferro, C.A.T. (2005). Simple Techniques for describing changes in probability distributions of weather and climate. Journal of Climate (in press).

Giorgi, F., B $\mathrm{B}_{\mathrm{i}}$ X.Q. and Pal, J. (2004). "Mean, Inter-annual Variability and Trends in a Regional Climate change Experiment over Europe, II". Climate change Scenarios 
(2071-2100), Climate Dynamics, 23: 839-858.

Griffin, D.L. (2001). “Aridity and Humidity: Two aspects of the late Miocene Climate of Northern Africa and the Mediterranean". Elsenier Science Canada.

Inter-Governmental Panel on Climate Change working Group 1 Report (1990). Cambridge University Press London

Jeje, L.K. (1978). "Aspect of the Geomorphology of Nigeria" in Oguntoyinbo, J.S., Areola, O.O. and Filiani, M.(ed).(1978). Geography of Nigeria Development $2^{\text {nd }}$ edition, Heinemann Education Books (Nig) Ltd.

Kjellstrom, E. (2004). Recent and Future Signatures of Climate change in Europe. Ambio, 33: 193-198.
McGregor, G.R., Ferro, C.A.T and. Stephenson, D.B. (2005). "Projected Changes in Extreme Weather and Climate Events in Europe". In: Kirch W, Menne B., Bertollini R. Extreme Weather and Climate Events: Public Health Responses. Springer, Heidelberg, pp 13-23.

Oladipo, E.O. (1991). Potential Impacts of Climatic Change Nigeria. Paper Presented at the Geography week of NAGS. ABU, Zaria.

Xue, Y. and Shukla, J. (1997). "The Influence of Land Surface Properties on Sahel Climate. Part 1: Desertification", J. Climate 6: 2232-2245. 